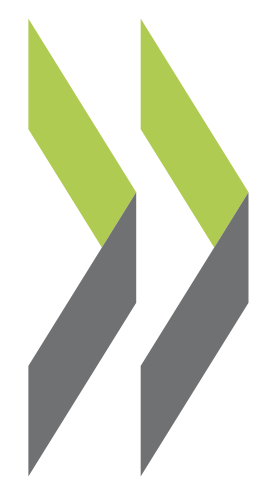

CELE Exchange, Centre for Effective Learning Environments 2009/06

\title{
Portugal's Secondary School Modernisation Programme
}

Teresa V. Heitor, José M. R. Freire da Silva 


\title{
Portugal's Secondary School Modernisation Programme
}

\author{
By Teresa V. Heitor and José Freire da Silva, Parque Escolar, Portugal \\ with Teresa Calçada, Vitor T. Teodoro and Paulo Renato Trincão
}

The aim of the Secondary School Modernisation Programme, being implemented in Portugal by Parque Escolar, EPE, is based on the pursuit of quality and makes Portuguese education a potential international benchmark. This paper discusses the strategies adopted to reorganise school spaces. It describes the conceptual model and highlights the solutions proposed for libraries, science teaching spaces and museum units.

The modernisation programme, created by a Resolution of the Council of Ministers in January 2007, refurbishes physical infrastructure, opens up schools to the community, and maintains and manages the buildings after refurbishment. The programme is expected to be introduced in a total of 332 schools by 2015 .

Modernising school premises highlights the importance of physical space and its habitability. The programme aims to create attractive spaces that can foster well-being, can ensure the essential conditions for teaching - consistent with the educational values promoted by the curriculum-, and can contribute to learning, performance, and comfort and safety among the student population, as well as among teachers and other staff.

The Secondary School Modernisation Programme strengthens architectural design and the organisation, management and maintenance of the various school spaces. The school building model adopted for the programme is not a standardised building, but rather one which reflects the educational project pursued by each school, so as to respond adequately to the needs, objectives and characteristics of the school communities and ensure the initiative's durability and sustainability over the long term.

To develop new architectural solutions for the schools covered by the programme, Parque Escolar held meetings with a multidisciplinary team of consultants, including researchers and teachers from various scientific areas, in addition to architects.

\section{THE CONCEPTUAL MODEL}

The education model adopted in Portugal aims to produce schools that focus on imparting knowledge, transmitting information and providing skills to students, as well as furthering, encouraging, and supporting lifelong learning and training. The organisation of the school space defines the physical platform for all the activities it accommodates; in particular, it affects the way in which the different members of the school community (students, teachers, administrative staff and other educational partners) interact, in terms of learning and acquiring diverse skills and knowledge. 


\section{Figure 1. Diagram of the conceptual model for functional-spatial organisation}

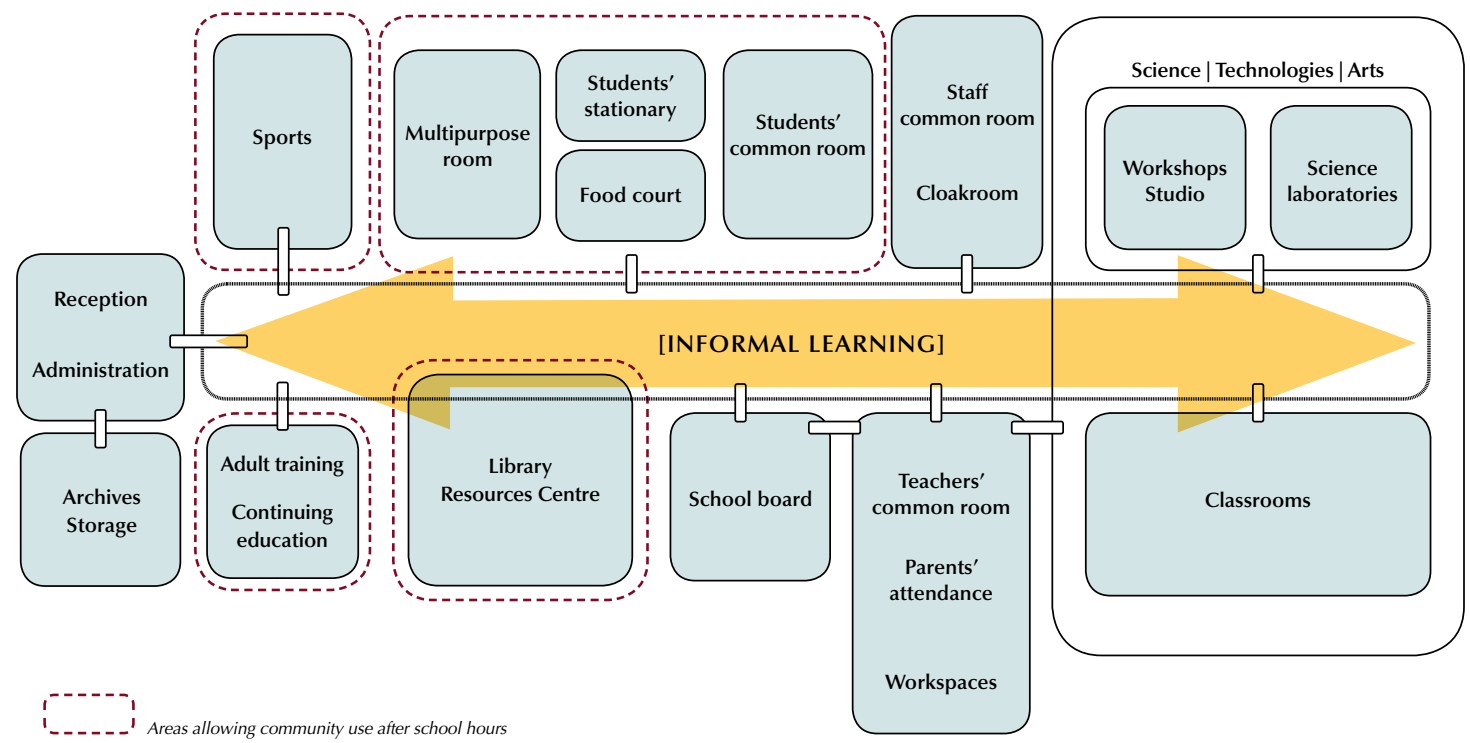

The conceptual model adopted by Parque Escolar is shown in Figure 1. It is based on:

1. providing the following:

- formal learning spaces including both general-purpose classrooms and dedicated rooms such as laboratories, workshops, art studios, and information and communications technology (ICT) rooms, which can be adapted to the different types of pedagogical practice;

- informal learning spaces (not confined to the classroom);

- indoor and outdoor social and recreational spaces for informal encounters and extra-curricular activities;

- social and work spaces for teachers and staff;

- areas for exhibiting students' work and other didactic materials;

- administrative and attendance areas.

2. making areas available to the wider community after school hours, specifically:

- rooms for adult training and skills certification;

- library/resource centre and museum units referred to as "memory and knowledge spaces";

- multipurpose room/auditorium;

- food court (bar/canteen);

- sports and physical education areas.

3. closely interlinking teaching and non-teaching areas;

4. centrally positioning the informal learning core space, including the library/resource centre, social spaces, and memory and knowledge spaces. 
Figure 2 shows the new spatial layout. The key concept behind it is two interconnected structural rings. A shallow ring connects all the school spaces that are available to the community after school hours, and a deeper ring intertwines the teaching core with teachers' workspaces. These two rings intersect at the informal learning core space.

\section{Figure 2. Diagram of the spatial layout}

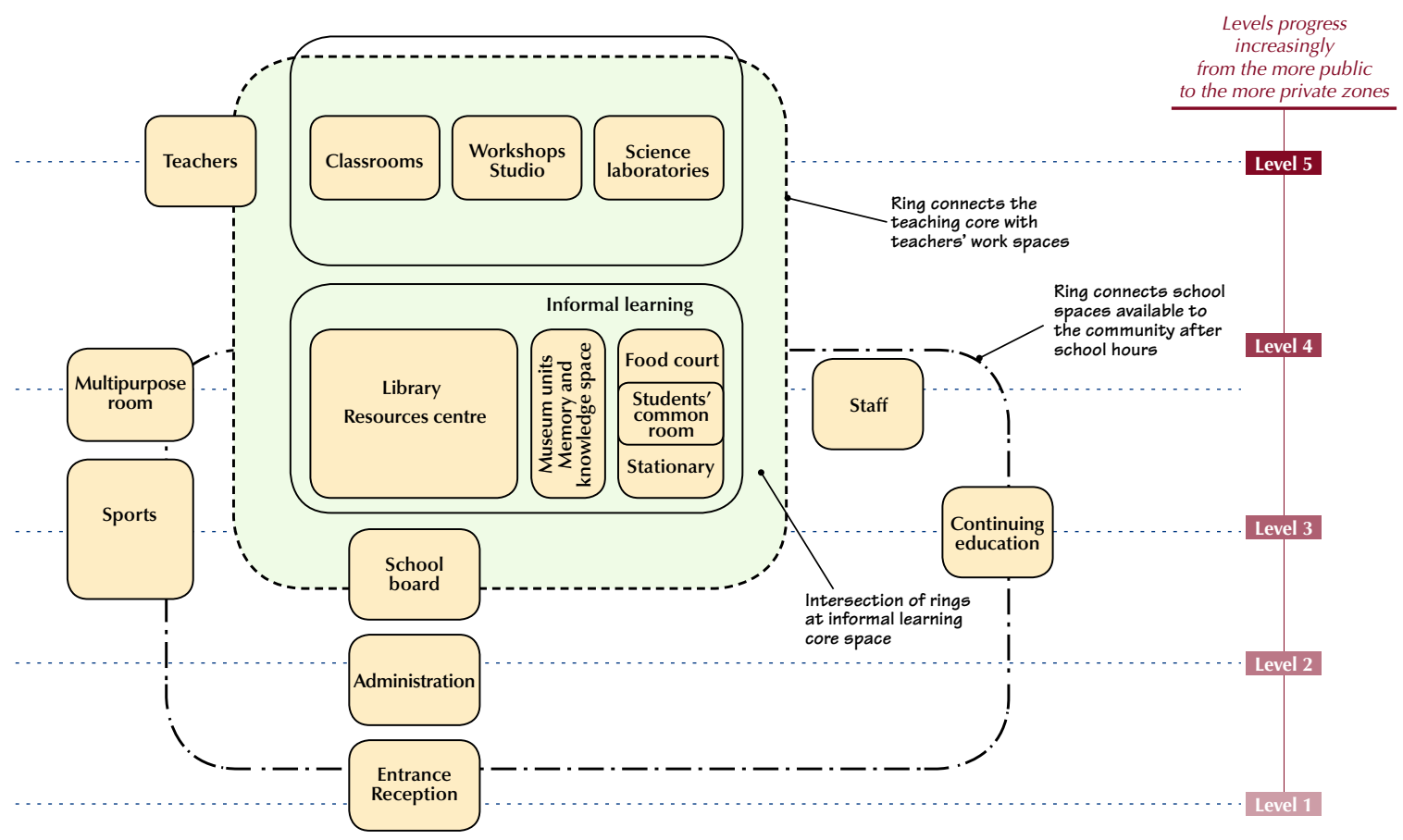

\section{LIBRARIES}

The model that has been adopted places the library at the heart of the school: a central space both physically and symbolically. The message is that of a workspace, containing books and a variety of other information sources, which is open and comfortable and where everyone is welcome for personal reading and multimedia access, as well as group work.

In addition to occupying a privileged location at the school's functional and symbolic centre, the library reflects the principles of functionality, size and ambient comfort proposed by the School Libraries Network. The aim is to make the space highly flexible; to allow for varied use, extended to the community at large, as well as to people with impaired mobility and special educational needs; and to adapt over time to new requests, arising from population growth and both curricular and technological changes, through low-cost alterations. 
The space assigned to the library is defined in terms of the number of students and subdivided into five areas:

1. Core area, consisting of four zones:

- reception area for the counter service, the lending service, and a catalogue consultation and information terminal, located near the entrance and affording visual control of the other public areas;

- informal reading area for periodicals, illustrated books and works of fiction, located near the entrance;

- document consultation area for integrated use of documentation on different media, including audio, video playback equipment and portable computers, offering individual and group work facilities;

- multimedia consultation and production area for integrated use of information technology equipment (computers, scanners, printers, webcams, cameras and digital video cameras), with individual and group work facilities;

2. Document management and processing area where library staff process documentation; its location allows visual access to the core area;

3. Multipurpose area intended for multimedia presentations, lectures, debates and curricular support activities in small groups or classes, independently accessible from outside;

4. Storage area for deposited materials;

5. Exhibition area for temporary displays of thematic content, integrated into the circulation area with access to the core area.

\section{Figure 3. School library diagram}

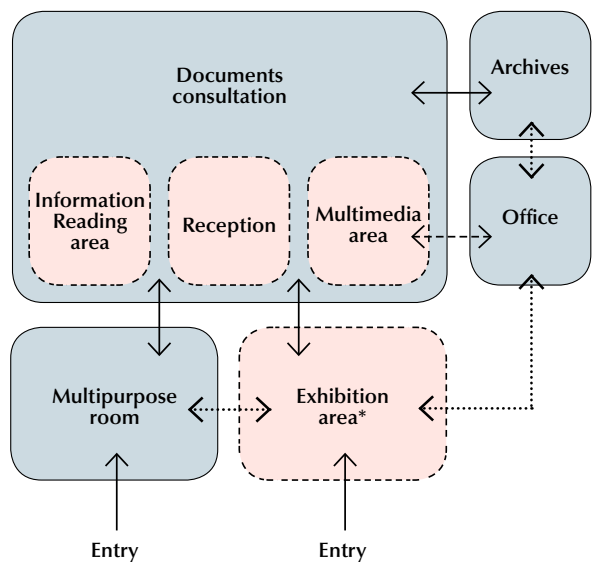

$\longrightarrow$ Physical access

$----->$ Physical and visual access

……... Optional access

- - Mobile division that allows visibility throughout the entire space

* This area is not part of the library; it can occupy an exterior circulation area serving as an entrance to the library. 
In library spaces, special attention is given to ambient comfort, particularly in terms both of acoustics, to block out external noise and control internal noise generated by use, and of lighting, excluding direct sunlight in the library space and adapting artificial lighting to the nature of functional areas.

The electricity and communications network is planned in terms of functional areas, number of users, support services and future changes or expansion, with wireless Internet access available in all areas. Fire-resistant and non-combustible materials are also used, and a fire-fighting system is provided for (smoke detectors, automatic sprays, strategically placed fire extinguishers and signing to help users in emergency situations).

The furniture and equipment are tailored to the different areas and functional zones. They target the users in each case, and also meet robustness and flexibility criteria.

For further information on the library area, contact the consultant team co-ordinator, Dr. Teresa Calçada, School Libraries Network, e-mail: teresacalcada@rbe.min-edu.pt.

\section{SCIENCE TEACHING SPACES}

In most Portuguese schools, areas for teaching science - physics, chemistry, biology and geology - have exclusive laboratories attached to rooms used for preparing and storing materials and equipment. They are generally located in parts of the building that have limited access and afford low levels of visibility in relation to the rest of the school. In addition to the physical wear and tear they are subjected to and the need for more infrastructure of this type, they can quickly show signs of obsolescence caused by changes in the original conditions of use, changes in curricula and experimental practices, and the use of computer-based media. A rigid spatial organisation with fixed furniture inhibits different types of teaching-learning practice, and makes it difficult to adapt to situations which require a more active learning style.

The model adopted promotes specific spaces for science teaching that are physically and visually accessible to the rest of the school, are designed to allow diverse ways of teaching, and facilitate various types of experimental, practical and hands-on work, alongside individual or group-based research. Creating learning opportunities in the science areas - in particular, adaptable and stimulating environments - not only contributes to educational performance, but also helps arouse students' interest and involvement.

The proposed solutions take account of an analysis of school curricula and of recent developments in designing school spaces, specifically in the United Kingdom, and the results of a joint reflection between teachers, architects, engineers, suppliers of laboratory furniture and equipment, and specialists in teaching and disseminating the sciences.

Apart from correcting construction problems and improving conditions of ambient comfort, the aim is to adapt laboratories to current teaching needs, in particular those resulting from the existence of twoshift classrooms, science clubs and new non-academic curricular areas, together with integrating ICT and computer-assisted activities. 


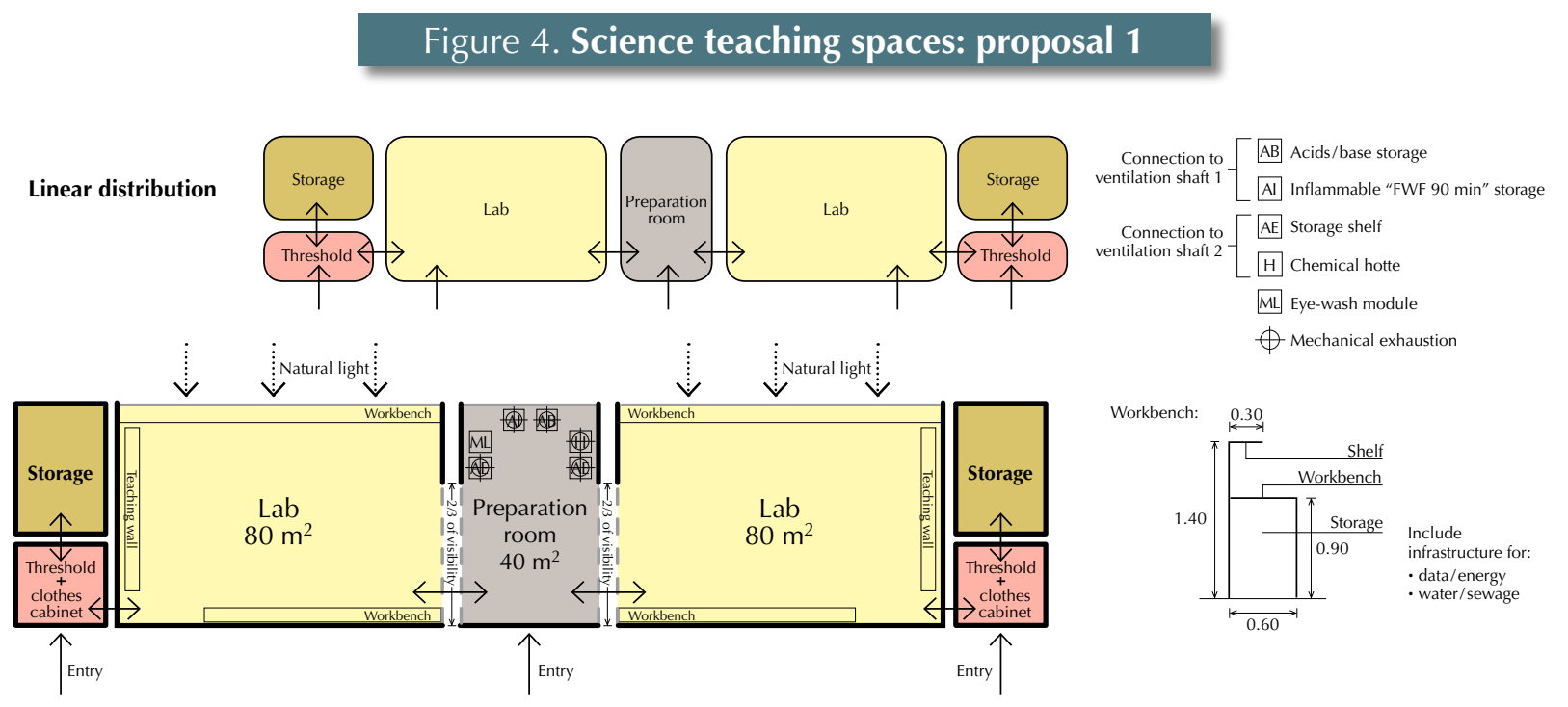

\section{Figure 5. Science teaching spaces: proposal 2}
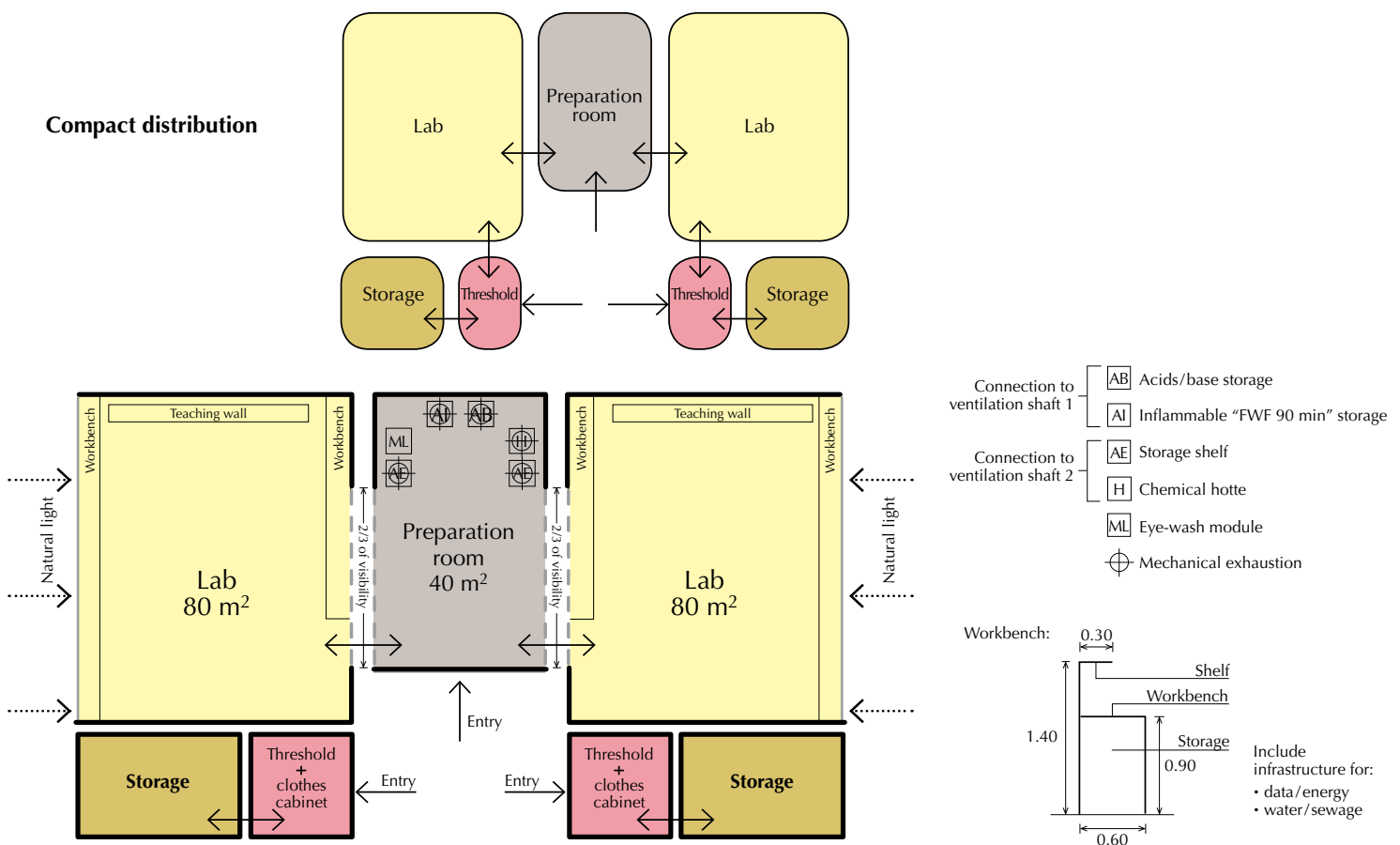

The main characteristics of the laboratories are as follows:

- Laboratories exist in pairs, wherever possible with a common support room between them where shareable equipment can be kept (e.g. mobile fume hood, reagent cupboards, tool cupboard).

- Transparent walls provide visibility between laboratories and support rooms, wherever possible. 
- The laboratories have a flexible spatial organisation, with wide and movable work benches $(0.80 \mathrm{~m} \times 1.80 \mathrm{~m})$ allowing three to six students to work standing up or seated on stools.

- The side walls have fixed work surfaces with water supply, cable conduits and full-length shelving. There are storage cupboards above the work benches.

- The movable work benches can be arranged in different ways, and placed separately or alongside the lateral work surfaces, quickly and quietly.

- The surfaces of the lateral work benches are resistant to the main chemical products and to fire.

- Some equipment, for example the fume hood, can be moved from the support room to either of the laboratories. The interior of the fume hood is visible through any of its lateral faces.

- All laboratories have Internet access, a computer and projector.

- The whiteboard also serves as a computer projection screen and extends along the entire front wall a teaching wall - forming part of a large storage area.

- Spaces are provided in the hall at the laboratory entrance for various storage needs, including school bags and coats.

- The laboratories respect safety standards and include active safety equipment.

- Laboratories can be used with half or all of the students from a class.

- All classes can be given in the laboratory, including small-group, large-group or demonstration activities, or even theoretical classes.

To accompany the work in the schools, a website ( $h t t p: / /$ laboratoriosescolares.net) has been developed for teachers, containing information on the concepts used in the design of science teaching areas, conditions of use, equipment and ways of using the spaces provided.

For further information on science teaching spaces, contact the consultant team co-ordinator, Prof. Vítor Teodoro, Education and Development Research Unit (UIED), Faculty of Science and Technology, The New University of Lisbon, e-mail: vtd@fct.unl.pt.

Laboratory front wall, with whiteboard and storage spaces
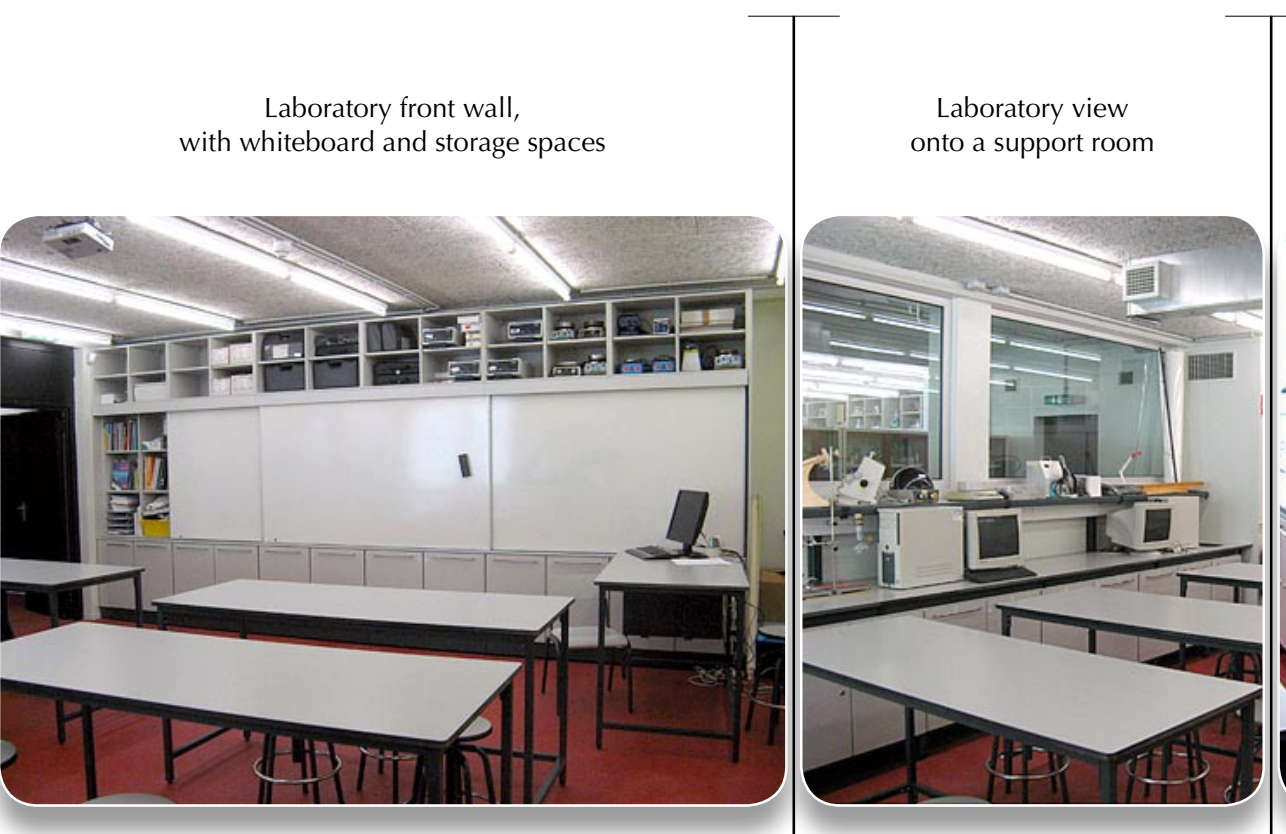

Laboratory computer and projector

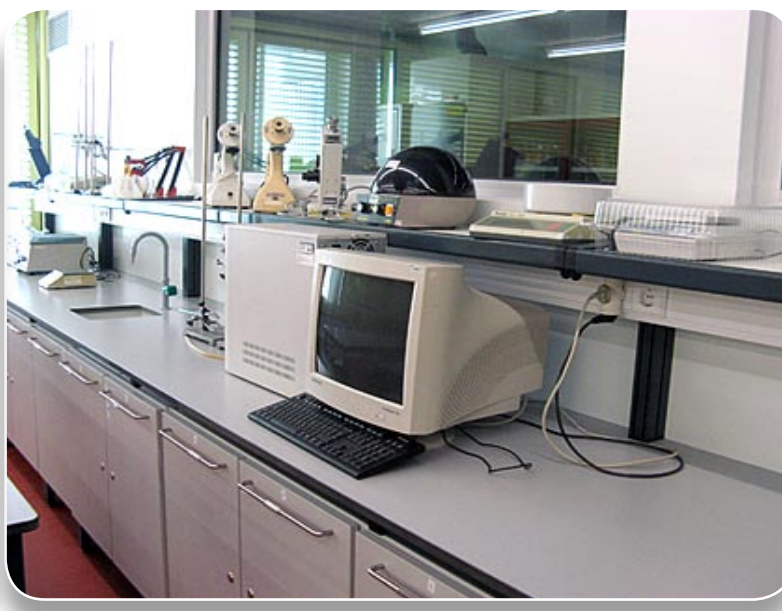




\section{MUSEUM UNITS}

Museum collections in schools require organising their permanent and/or temporary exhibits in a didactic way.

Originally, school pedagogical museums were essentially concerned with the operational needs of teaching materials and equipment. Collections accumulated in encyclopaedic fashion. Another concern (not equally shared by all schools) was to conserve the school's artistic heritage and furniture.

For these reasons, many teaching establishments have set up formal or informal museum units in various phases of their history. Collections most frequently consist of zoological and geological materials (animals embalmed or conserved in formalin, minerals, rocks and fossils); obsolete didactic and pedagogic materials (apparatus for physics, chemistry and geography experiments, wall posters); and scientific instruments (old microscopes). Other elements considered identity-defining at different times are usually kept in these museum spaces (paintings, ceramics, textiles, maps, sculptures, pieces of furniture and photographs, students' work, trophies).

Such materials seldom have any pedagogic use, although they may sometimes be used to decorate corridors or hallways.

Based on this reality, a comprehensive physical model was developed to define a new functional programme for and make use of old museum spaces in schools, to be known as "memory and knowledge spaces".

The key concept is based on two concentric structural rings, referred to as the knowledge ring (external) and the memory ring (internal). The knowledge ring is entered by passing through the memory ring. These two rings define independent areas, each with its own function. Several workgroups can occupy them simultaneously.
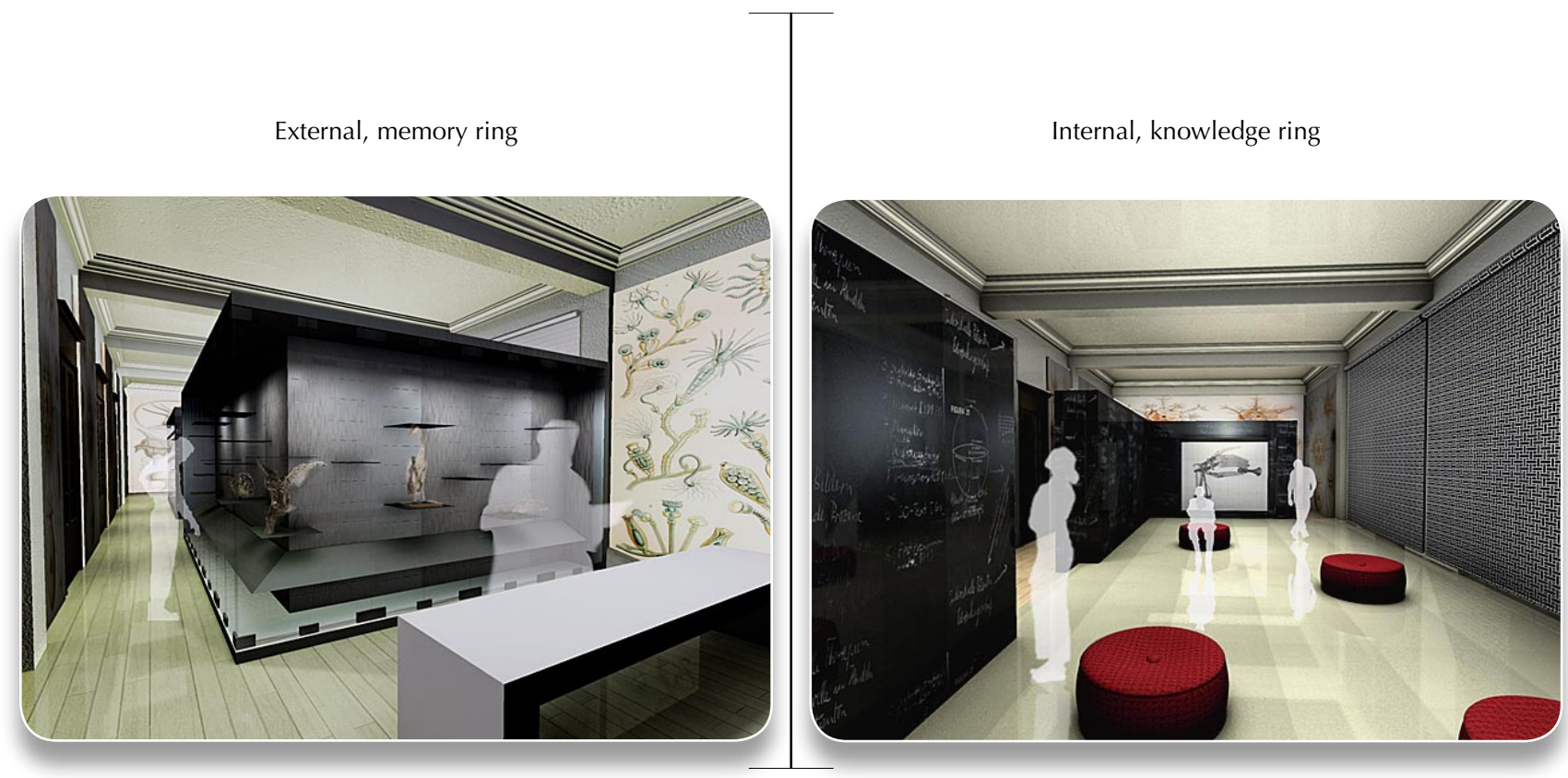
The external ring, or memory ring, consists of glass cabinets exhibiting selected objects from the museum collection. The ring of cabinets has a gap giving access to the interior, semi-private space they create. The system of shelving and replaceable labelling allows the exhibits on display to be easily changed. This area includes two tables for displaying particular objects chosen by teachers or users. The external ring is regularly supplied from the museum collection which is kept in a store room outside the exhibition, thereby making it possible to rotate exhibits.

The internal ring, or knowledge ring, consists of a smooth wall formed by the backs of the cabinets. It contains audiovisual and multimedia equipment and is intended for exhibitions, debates, presentation of work and screening of audiovisual materials. This area is designed to have movable seats with a capacity for about 30 people (using easily transportable chairs). It is carpeted so that students can sit on the floor for additional informality. A series of panels with old scientific illustrations decorate the surrounding walls, thereby strengthening the historical and museum ambience.

This model can easily be reproduced even in schools that have an organised museum unit. Not only does it make reusing museum spaces possible, but it also encourages the construction of exhibitions and interdisciplinary work based on existing and currently displayed items from the collection.

For further information on the memory and knowledge spaces, contact the consultant team co-ordinator, Prof. Paulo Renato Trincão, Research Centre for Didactics and Technology in Teacher Education (CIDTFF), University of Aveiro, e-mail: paulo.trincao@ua.pt.

For more information, contact:

Teresa V. Heitor, Architect, MSc, PhD

Parque Escolar, EPE

Av. Infante Santo, 2, $7^{\circ}$ piso

1350-178 Lisbon

Portugal

E-mail: teresa.heitor@parque-escolar.min-edu.pt

José Freire da Silva, Architect

Parque Escolar, EPE

Av. Infante Santo, 2, $7^{\circ}$ piso

1350-178 Lisbon

Portugal

E-mail: jose.freire@parque-escolar.min-edu.pt

See also "Modernising Portugal's Secondary Schools", PEB Exchange, 2008/1. 


\section{ORGANISATION FOR ECONOMIC CO-OPERATION AND DEVELOPMENT}

The OECD is a unique forum where the governments of 30 democracies work together to address the economic, social and environmental challenges of globalisation. The OECD is also at the forefront of efforts to understand and to help governments respond to new developments and concerns, such as corporate governance, the information economy and the challenges of an ageing population. The Organisation provides a setting where governments can compare policy experiences, seek answers to common problems, identify good practice and work to co-ordinate domestic and international policies.

The OECD member countries are: Australia, Austria, Belgium, Canada, the Czech Republic, Denmark, Finland, France, Germany, Greece, Hungary, Iceland, Ireland, Italy, Japan, Korea, Luxembourg, Mexico, the Netherlands, New Zealand, Norway, Poland, Portugal, the Slovak Republic, Spain, Sweden, Switzerland, Turkey, the United Kingdom and the United States. The Commission of the European Communities takes part in the work of the OECD.

OECD Publishing disseminates widely the results of the Organisation's statistics gathering and research on economic, social and environmental issues, as well as the conventions, guidelines and standards agreed by its members.

This work is published on the responsibility of the Secretary-General of the OECD. The opinions expressed and arguments employed herein do not necessarily reflect the official views of the Organisation or of the governments of its member countries.

You can copy, download or print OECD content for your own use, and you can include excerpts from OECD publications, databases and multimedia products in your own documents, presentations, blogs, websites and teaching materials, provided that suitable acknowledgment of OECD as source and copyright owner is given. All requests for public or commercial use and translation rights should be submitted to rights@oecd.org. Requests for permission to photocopy portions of this material for public or commercial use shall be addressed directly to the Copyright Clearance Center (CCC) at info@copyright.com or the Centre français d'exploitation du droit de copie (CFC) at contact@cfcopies.com. 